\title{
Viabilidade da aplicação do GPR para o mapeamento de camadas de bauxita laterítica e de goethita
}

\author{
Gildenilson Mendes Duarte ${ }^{1 *}$, José Gouvêa Luiz, Marcos Welby Correa Silva ${ }^{1}$, Clóvis Maurity ${ }^{2}$
}

\begin{abstract}
Resumo O método eletromagnético GPR foi testado no mapeamento de camadas em depósitos de minérios, localizados em dois diferentes ambientes geológicos. Foram realizadas medidas com o intuito de mapear camadas que compõem depósitos de origem supergênica de bauxita laterítica e goethita. Os levantamentos para o mapeamento das camadas de bauxita foram realizados no município de Paragominas, no Pará. As medidas para o mapeamento das camadas de goethita foram realizadas no interior de uma fazenda particular, localizada entre os municípios de Xambioá e Vanderlândia, estado do Tocantins, próximo ao Cinturão Araguaia. O estudo teve como principal objetivo identificar os parâmetros profundidade e espessura das zonas mineralizadas, que podem auxiliar no trabalho de explotação dos minérios. Os resultados obtidos podem ser considerados bastante satisfatórios, pois o método apresentou boa resposta para os dois tipos de minérios investigados, tornando-se possível a caracterização das camadas e a verificação de suas profundidades e espessuras.
\end{abstract}

Palavras-chave: geofísica aplicada; método GPR; depósito de bauxita; depósito de goethita; exploração de minérios.

\begin{abstract}
Viability of GPR application for the mapping of layers of lateritic bauxite and goethite. The GPR electromagnetic method was tested in the mapping of layered mineral deposits, located in two different geological environments. Measurements were made with the aim of mapping layers that form the deposits of supergene origin of lateritic bauxite and goethite. The surveys for the mapping of the bauxite layers were conducted in the municipality of Paragominas, in Pará State. The measurements for mapping the goethite layers were carried out inside a private property, which is located between the towns of Xambioá and Vanderlândia, Tocantins State, near the Araguaia Belt. The study had as main objective to identify the parameters depth and thickness of the mineralized zones, which may help in the work of exploitation of the ores. The obtained results can be considered as very satisfactory, because the method presented a good response for both types of ores investigated, making possible the characterization of the layers and the verification of their depths and thicknesses.
\end{abstract}

Keywords: applied geophysics; GPR method; bauxite deposit; goethite deposit; exploration of ores.

INTRODUÇÃOO O estudo das rochas, que ocorrem na superfície do solo bem como de suas relações no espaço e no tempo, é de fundamental importância para a compreensão das rochas da subsuperfície e para a localização dos depósitos de minérios. Contudo, os afloramentos nem sempre podem fornecer informações seguras sobre a subsuperfície e, em alguns locais, podem não se encontrar disponíveis devido ao processo de intemperismo ali presente.

Geralmente, as rochas se diferem entre si por meio de suas propriedades físicas, o que provoca variações na propagação de ondas que incidam sobre as mesmas. Devido a estas variações, podemse adquirir informações acerca dos materiais que as provocaram (Luiz \& Silva 1995). Métodos que se utilizam de ondas eletromagnéticas, por exemplo, são bastante empregados na prospecção de minérios, permitindo a localização de depósitos que repousam a profundidades superiores a $500 \mathrm{~m}$.

No presente trabalho, empregou-se o método eletromagnético do radar de penetração no solo (Ground Penetrating Radar ou GPR). Este não é comumente utilizado na prospecção mineral, devido a sua pequena profundidade de exploração (geralmente inferior a $30 \mathrm{~m}$ ), mas permite a discriminação de alvos de pequenas dimensões e fornece uma seção da subsuperfície, na forma de imagem em alta resolução. O imageamento da subsuperfície rasa em alta resolução resulta das altas

\footnotetext{
${ }^{1}$ Universidade Federal do Pará - UFPA, Programa de Pós-graduação em Geofísica, Belém (PA), Brasil. E-mail: gildenilsonmd@, gmail.com,gouvea@ufpa.br,welby@ufpa.br

${ }^{2}$ Vale, Paragominas (PA), Brasil. E-mail: clovis.maurity@vale.com

*Autor correspondente
} 
frequências (normalmente de 10 a $2.500 \mathrm{MHz}$ ) empregadas no GPR, em contraste com aquelas geralmente inferiores a $5.000 \mathrm{~Hz}$, que são empregadas nos métodos eletromagnéticos que investigam grandes profundidades.

Embora o GPR seja pouco empregado na prospecção mineral, existem alguns exemplos de sua aplicação. Os seguintes autores descrevem esse tipo de aplicação: Porsani et al. (2004) o aplicou para pláceres com cassiterita em Rondônia, no Brasil; Ekes et al. (2002) e Hickin et al. (2007) o aplicou na detecção de pláceres auríferos e diamantíferos da Guiana; Botelho (2007) o aplicou na prospecção de manganês no Oeste do estado da Bahia (Além São Francisco), Brasil; Silva et al. (2010) o aplicou na investigação de mineralização de bauxita na região de Trombetas, Pará, no Brasil.

A escolha do GPR para este estudo ocorreu devido ao objetivo da aplicação, que é mapear em detalhe as camadas de bauxita laterítica e de goethita, localizadas a pequenas profundidades, identificando-se os parâmetros profundidade e espessura, os quais podem auxiliar no trabalho de explotação e cubagem dos minérios.

\section{MÉTODO GPR O sistema GPR de medidas} consiste de um par de antenas, sendo uma transmissora e a outra, receptora, acopladas a uma unidade computacional, na qual visualiza-se, em alta resolução, uma imagem, chamada radargrama (perfil de reflexão). A antena transmissora irradia, continuamente, ondas eletromagnéticas para a subsuperfície, que sofrem refração, difração e reflexão ao interagirem com os materiais do meio. As ondas que retornam à superfície são captadas pela antena receptora. A profundidade de penetração da onda eletromagnética depende de sua frequência e das propriedades eletromagnéticas do meio investigado. Quanto maior a frequência da onda que penetra o solo, maior será sua interação com o meio e, portanto, maior será a dissipação de sua energia, o que ocasiona menor penetração (Luiz 1998). Por outro lado, a profundidade alcançada depende também das propriedades eletromagnéticas do meio. Por exemplo, se o meio for condutivo (zona de alta perda), a onda sofre atenuação alcançando uma profundidade pequena. As interfaces entre camadas visualizadas no radargrama são consequência da reflexão de parte da energia irradiada, que é provocada pela variação das propriedades eletromagnéticas do meio (Kearey et al. 2009). Outra característica do método está relacionada à resolução dos alvos que podem ser identificados. Quanto maior a frequência da onda, maior será a resolução obtida, permitindo-se a diferenciação de topo e base de camadas mais delgadas e de pequenos objetos.

No presente trabalho foram utilizadas antenas de $80 \mathrm{MHz}$ não blindadas e blindadas de 200 e $400 \mathrm{MHz}$, acopladas ao equipamento TerraSirch SIR System - 3000, da Geophysical Survey Sistems, operando nos modos tempo e contínuo. As medidas foram feitas ao longo de perfis de comprimentos, variando entre 50 e $100 \mathrm{~m}$, e com posicionamento controlado pela inserção de marcas no registro a intervalos de 5 a $10 \mathrm{~m}$. O processamento dos dados de GPR foi feito por meio do software Reflexw, versão 5.5.1 da K. J. Sandmeier. Tal processamento envolveu: correção estática; aplicação de ganho para compensação do decaimento de energia; estabelecimento de escala horizontal uniforme, por meio da redistribuição e interpolação de marcas de controle da distância; aplicação de filtro dewow para eliminar saturação do registro associada a ruídos de baixa frequência, provocados pelas ondas aéreas e diretas; aplicação de filtro de média móvel com média de cinco traços e aplicação de filtro de remoção de background para ressaltar variações laterais. A velocidade utilizada no processamento para a conversão de tempo em profundidade foi de $0,08 \mathrm{~m} / \mathrm{hs}$, para os levantamentos realizados no mapeamento de camadas de bauxita, e de $0,06 \mathrm{~m} /$ ns, para os dados coletados em Xambioá. Ambas as velocidades foram determinadas por meio de ajustes das hipérboles de difração, identificadas nos radargramas.

APLICAÇÃO À BAUXITA Os levantamentos para mapear as camadas de bauxita foram realizados na região da Província Bauxitífera de Paragominas, no Pará (Fig. 1), especificamente no interior da mina de bauxita da empresa Vale e sobre cortes localizados ao longo da Rodovia PA-256.

A região da Província Bauxitífera de Paragominas é caracterizada por formações sedimentares que sustentam os platôs, ou seja, as feições geomorfológicas dominantes na região (Kotschoubey et al. 2005). As informações obtidas 
pelos furos de sondagem mostram que o perfil litológico no interior da mina de bauxita da empresa Vale é composto por uma espessa camada argilosa (argila de Belterra), seguida de um horizonte pisolítico, uma camada de bauxita nodular, laterita ferruginosa, bauxita cristalizada, zona de bauxita cristalizada/amorfa, bauxita amorfa e, por fim, argila variegada. A Fig. 2 mostra o perfil litológico da área, destacando-se também a espessura de cada camada. Uma característica da zona mineralizada observada na área é a existência de três tipos de bauxita. Outra característica marcante na área estudada é a presença de camadas onduladas e descontínuas.

$\mathrm{Na}$ mina de bauxita, o levantamento com o GPR foi realizado na região denominada de Bloco F, no qual se localizam faixas de dimensões $20 \times 200 \mathrm{~m}$, que delimitam as zonas onde se processa a explotação do minério. Na Faixa 119, que contém capeamento argiloso de aproximadamente $12 \mathrm{~m}$ sobre o minério, foi executado o perfil $1 \mathrm{com} 50 \mathrm{~m}$ de comprimento (Fig. 3). O perfil 2, também com $50 \mathrm{~m}$ de extensão, foi realizado na Faixa 120, em zona sem capeamento (Fig. 3). Na Faixa 125, em zona sem capeamento, foram executados sete perfis com extensão de $100 \mathrm{~m}$, espaçados de 2,5 m (Fig. 4). Os perfis das Faixas 119 e 120 foram executados com antenas blindadas de $200 \mathrm{MHz}$, enquanto que, nos perfis da Faixa 125, foram usadas antenas blindadas de $400 \mathrm{MHz}$.

O perfil 1, mostrado na Fig. 5, realizado na Faixa 119 sobre o capeamento argiloso, não mostrou evidências das camadas que compõem a zona mineralizada, porque a onda do GPR foi atenuada pela argila do capeamento. É possível, entretanto, observar no perfil entre 1 e $3 \mathrm{~m}$ de profundidade: pequenas hipérboles no intervalo entre as posições 7 e $15 \mathrm{~m}$, que podem estar relacionadas à presença de pequenos corpos; e pequenas reflexões nos intervalos entre 20 e $25 \mathrm{~m}$ e entre 43 e $50 \mathrm{~m}$, que podem estar associadas a concreções ferruginosas bastante presentes na área.

O perfil 2, mostrado na Fig. 6, realizado na Faixa 120 diretamente sobre a zona mineralizada, mostra diversos refletores que foram associados à sequência de camadas mostradas na Fig. 2: bauxita cristalizada, bauxita cristalizada-amorfa, bauxita amorfa e argila variegada.

A Fig. 7 mostra o perfil central, dentre os sete executados na Faixa 125, sem a presença de

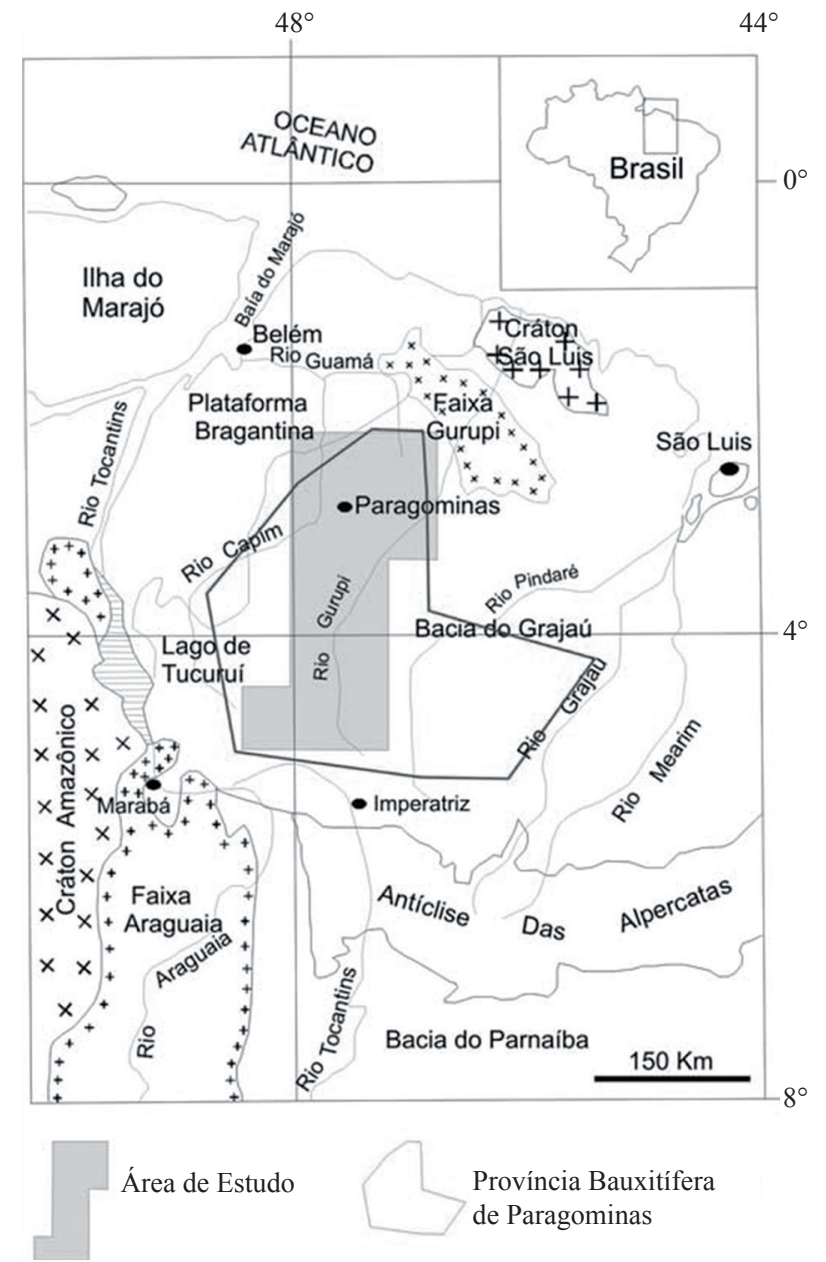

Figura 1 - Localização da área de estudo no mapeamento de camadas de bauxita. Modificado de Kotschoubey et al. (2005).

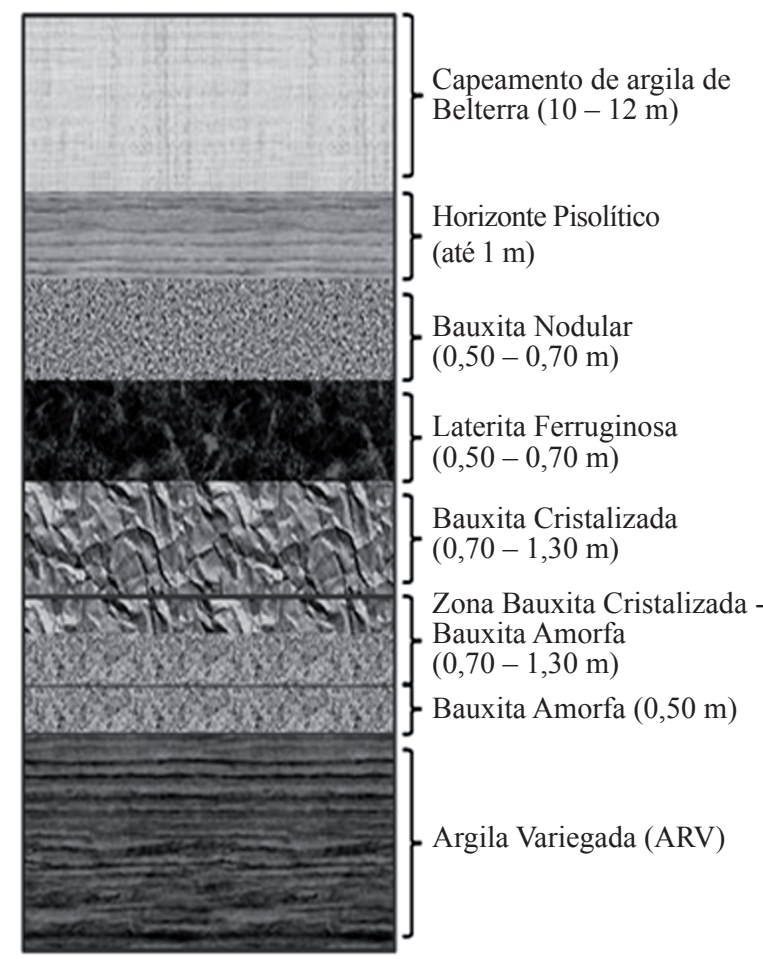

Figura 2 - Desenho esquemático do perfil litológico da área investigada dentro da mina com as espessuras estimadas das camadas. 
capeamento. Neste perfil, foram usadas antenas de $400 \mathrm{MHz}$ visando à obtenção de maior resolução. Observam-se, no perfil, as mesmas unidades identificadas no perfil 2, exceto a argila variegada basal. As interfaces que separam as unidades, entretanto, encontram-se mais onduladas do que aquelas do 2 .

Medidas também foram realizadas sobre cortes expostos ao longo da Rodovia PA-256 nos km 16 e 20 , fora da área da mina. A sequência litológica dessa área não é a mesma verificada no interior da mina de bauxita. Essa litologia é formada por uma camada de argila de Belterra no topo, seguida de camadas de laterita pisolítica, bauxita nodu-

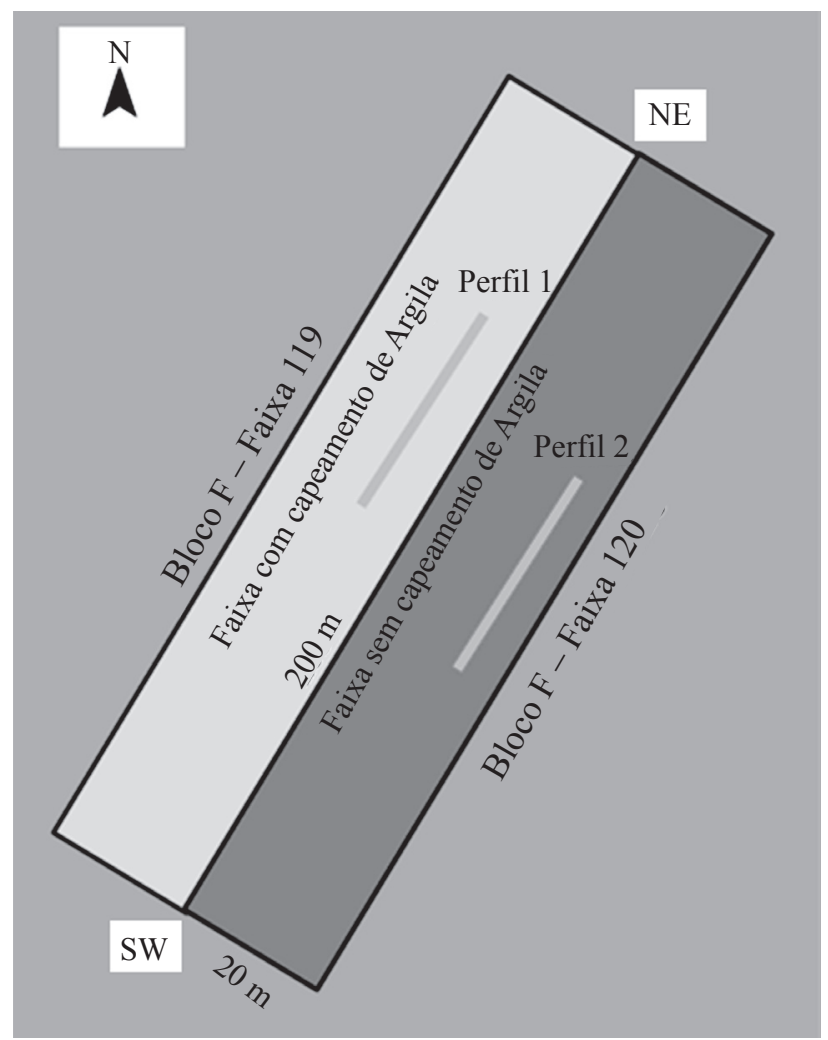

Figura 3 - Desenho esquemático de posicionamento dos perfis 1 e 2 nas Faixas 119 e 120. lar cristalizada, argila e bauxita laminar de fundo, como mostra a Fig. 8.

A Fig. 9 mostra o perfil realizado sobre o corte do km 16 da PA-256 (Fig. 8). No perfil, a interface de separação das camadas de argila de Belterra e laterita pisolítica não está bem definida. Somente a interface entre a laterita pisolítica e a bauxita nodular aparece bem definida ao longo de quase todo o perfil.

O mesmo pode ser observado na Fig. 10, que mostra o perfil executado sobre um corte localizado no km 20 da PA-256.

\section{APLICAÇÃO À GOETHITA As medi-} das de GPR para mapear o depósito de goethita foram realizadas no interior de uma fazenda localizada na BR-153, no trecho entre os $\mathrm{km} 29$ e 31, no sentido Xambioá-Vanderlândia, estado do

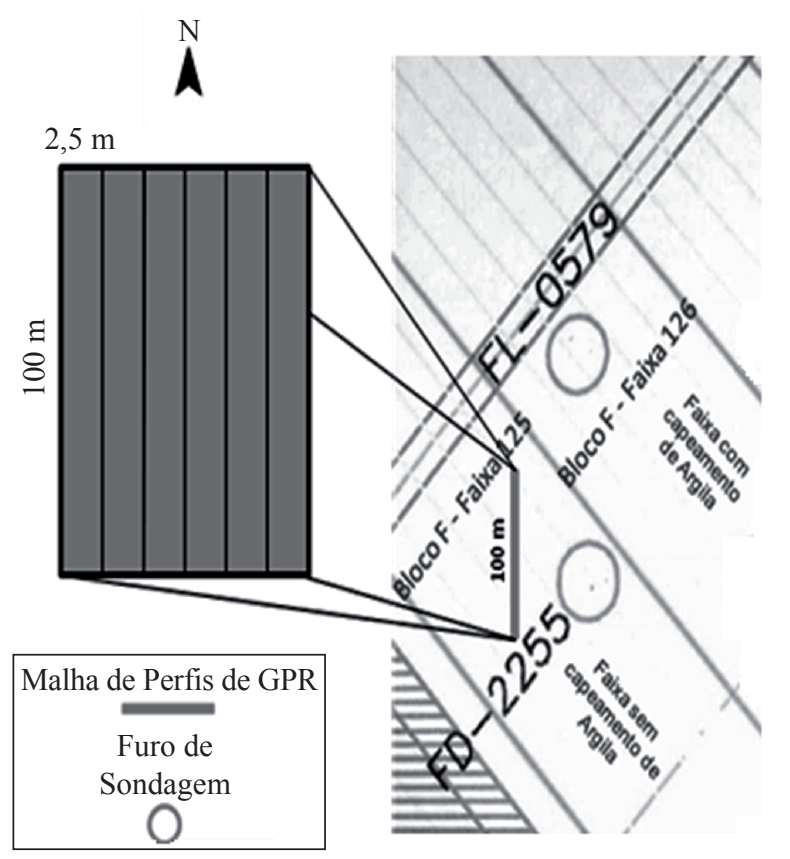

Figura 4 - Desenho esquemático mostrando a posição dos perfis GPR na Faixa 125.

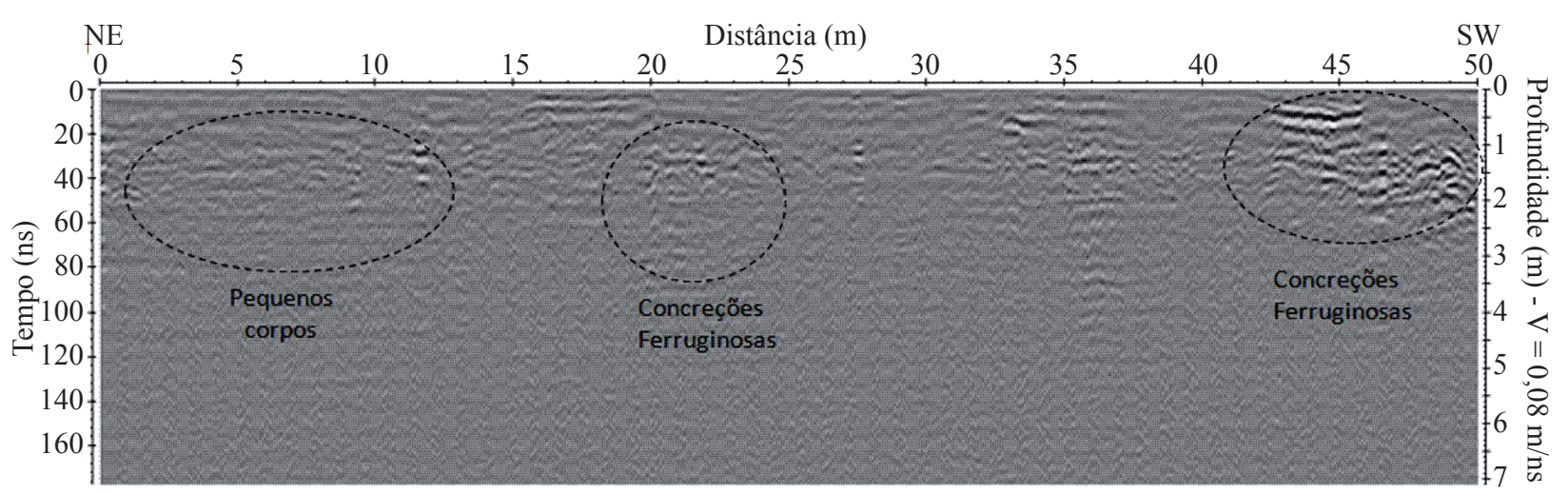

Figura 5 - Perfil 1 realizado com antenas de 200 MHz sobre o capeamento de Argila de Belterra, na Faixa 119. 


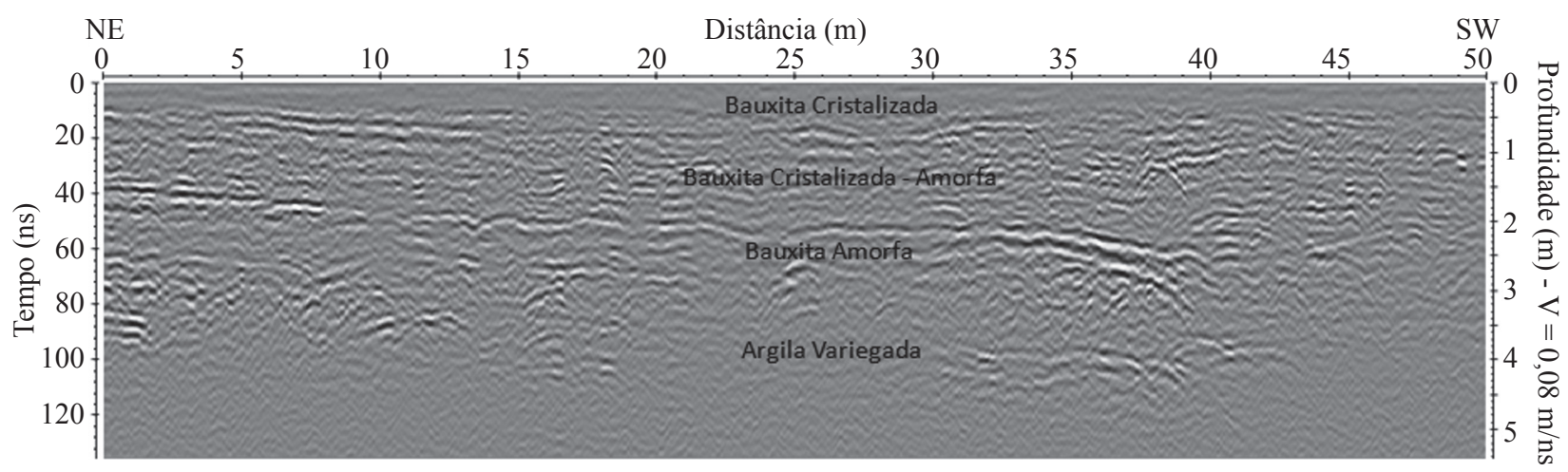

Figura 6-Perfil 2 realizado com antenas de 200 MHz sobre zona sem capeamento na Faixa 120.

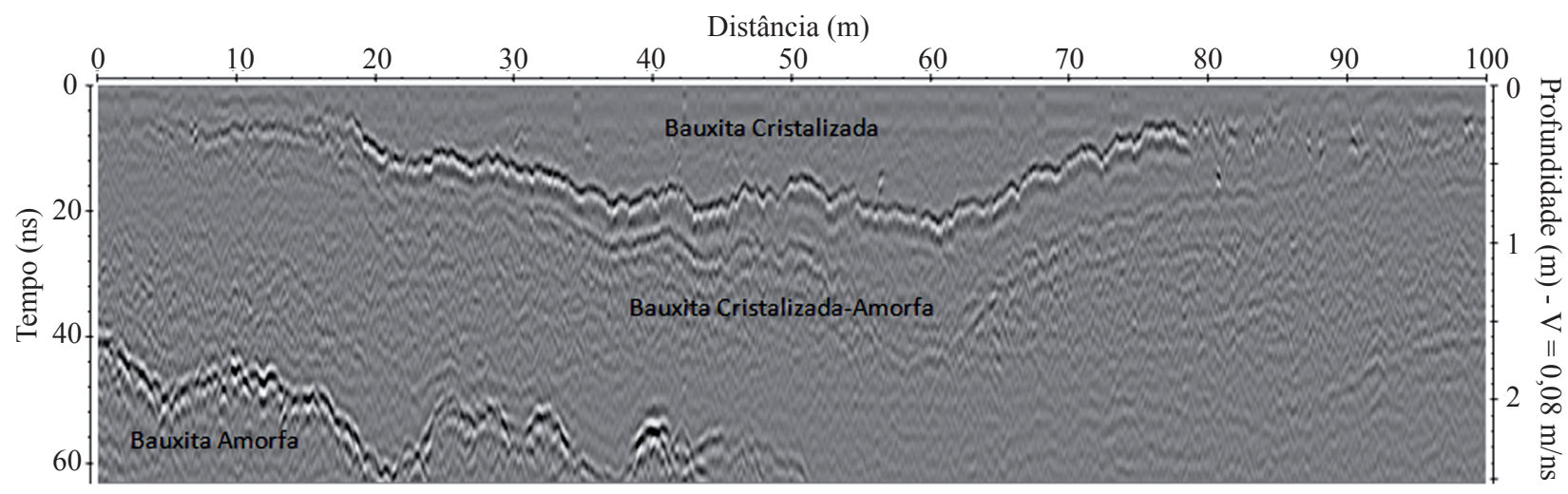

Figura 7 - Perfil central executado com antenas de 400 MHz na Faixa 125 sobre a camada de bauxita cristalizada.

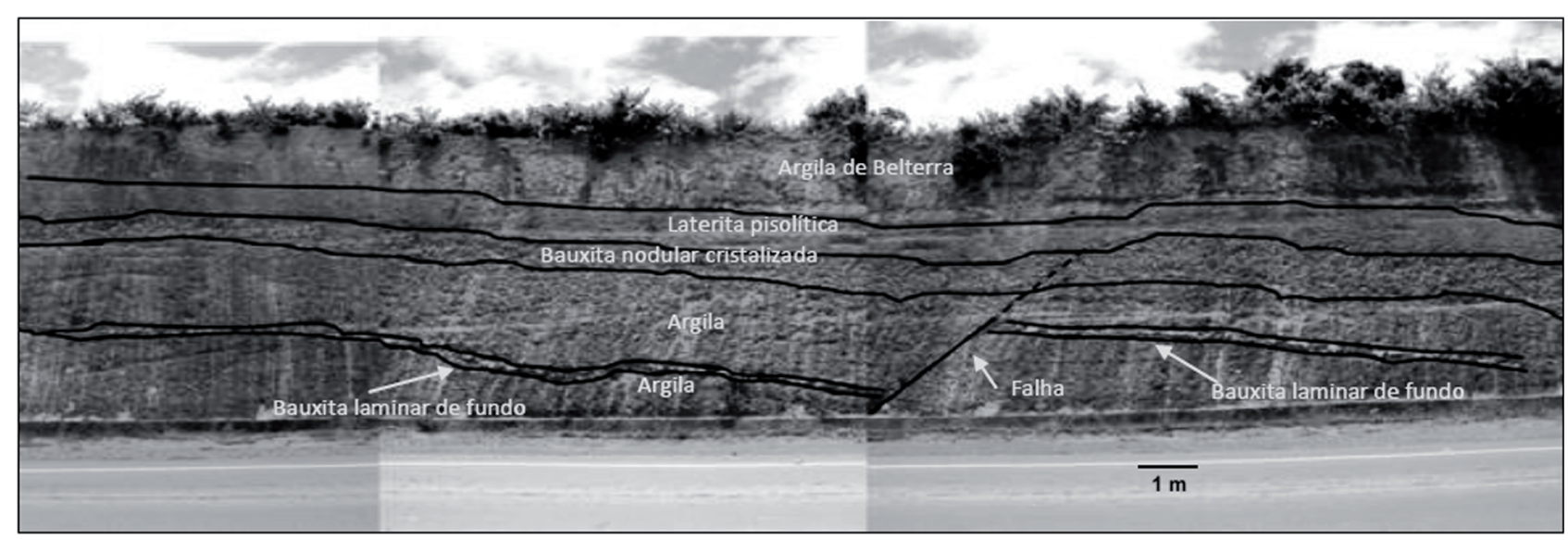

Figura 8 - Perfil litológico exposto no corte do $\mathrm{km} 16$ da Rodovia PA-256, utilizado como referência para a interpretação dos perfis realizados sobre os cortes da estrada. Fornecida pelo Geólogo Clóvis Maurity.

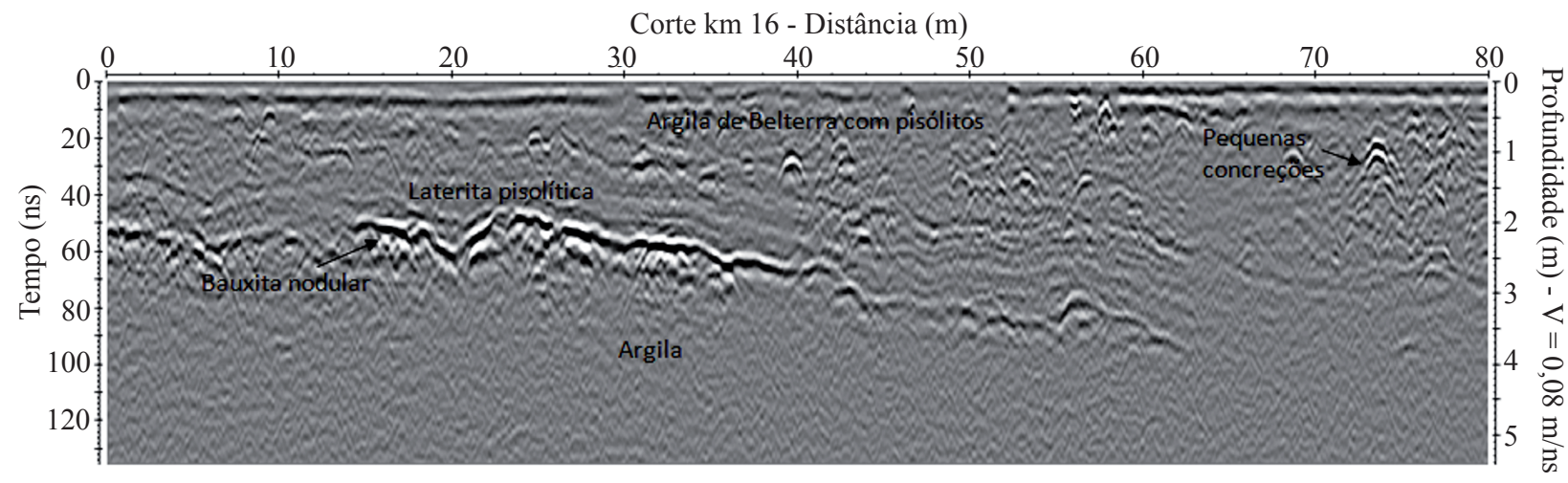

Figura 9 - Perfil realizado com antenas de 200 MHz sobre o corte do km 16 da Rodovia PA-256. 
Tocantins. Essa região pertence à Folha Xambioá (Fig. 11), que é situada sobre a Bacia do Parnaíba, próximo ao Cinturão Araguaia (CPRM 2008).

Na região de Xambioá, ocorrem sucessões de rochas sedimentares de unidades litoestratigráficas basais da Bacia do Parnaíba, as quais constituem áreas topograficamente elevadas, com características de platôs (CPRM 2008). Em vários locais, foram formadas crostas lateríticas, as quais capeiam serras e morros, tornando os topos mais resistentes à erosão. Essas formações ferríferas fazem parte da Formação Pimenteiras e repousam em discordância erosional sobre rochas metamorfisadas neoproterozoicas do Cinturão Araguaia. Estas também constituem camadas horizontalizadas de espessuras centimétricas a métricas. Apresentam textura oolítica, sendo que, quase sempre, os oólitos exibem estruturas concêntricas assimétricas em tons laranja e marrom e, em menor quantidade, há oólitos sem estruturação, ou seja, maciços. No entanto, são sempre constituídos de hematita e/ou goethita (Amaro 2011). Segundo informações obtidas por meio de furos de sondagem, a litologia local da área investigada é composta de camadas de goethita, seguida de uma de argilito siltoso, que está localizado sobre o embasamento de granito (Fig. 12).

Um teste em local próximo ao da área de levantamento, na qual era conhecida a estratigrafia, foi realizado com antenas não blindadas de $80 \mathrm{MHz}$ e com algumas blindadas de $200 \mathrm{MHz}$. O objetivo do teste foi verificar a espessura máxima da zona mineralizada e comparar a resolução na obtenção dos dados, para se ter maior segurança de que a zona mineralizada seria completamente mapeada.

A Fig. 13 mostra o perfil teste executado com antenas não blindadas de $80 \mathrm{MHz}$. No perfil, é possível visualizar a espessura máxima da zona mineralizada, que chega a aproximadamente $5 \mathrm{~m}$.

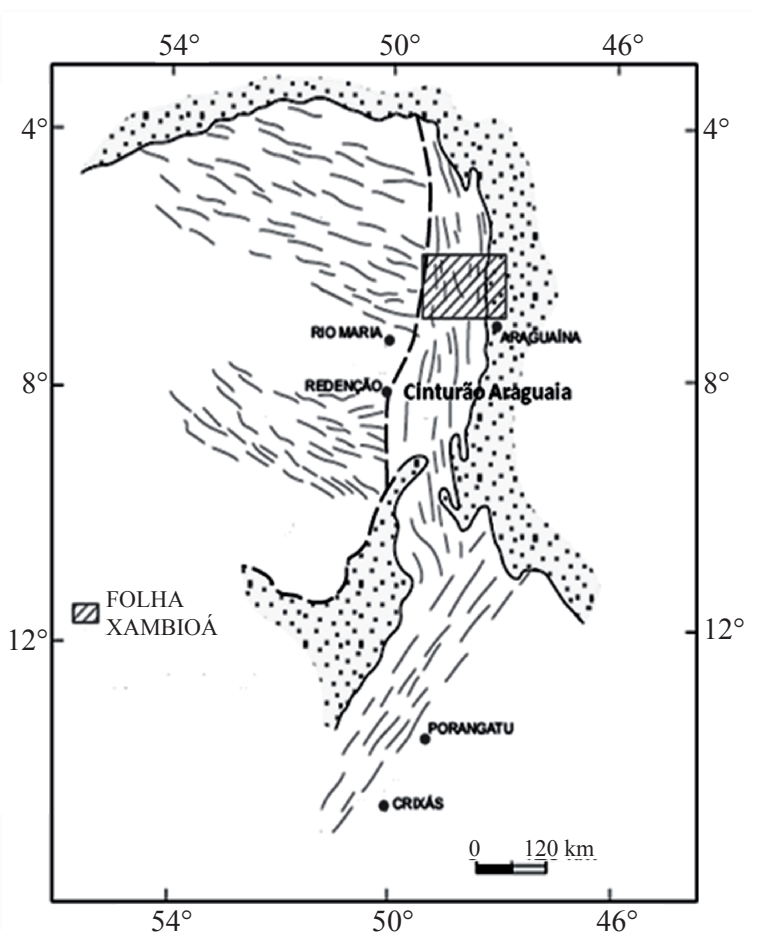

Figura 11-Localizaçãodaáreadeestudonomapeamento de camadas de goethita. Modificado de CPRM (2008).

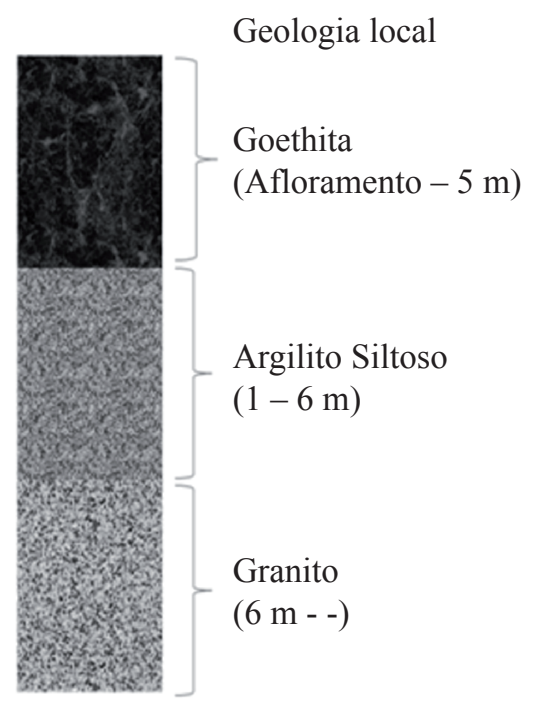

Figura 12 - Desenho esquemático do perfil litológico local da área de Xambioá. Informações fornecidas pelo geólogo Wagner Nascimento.

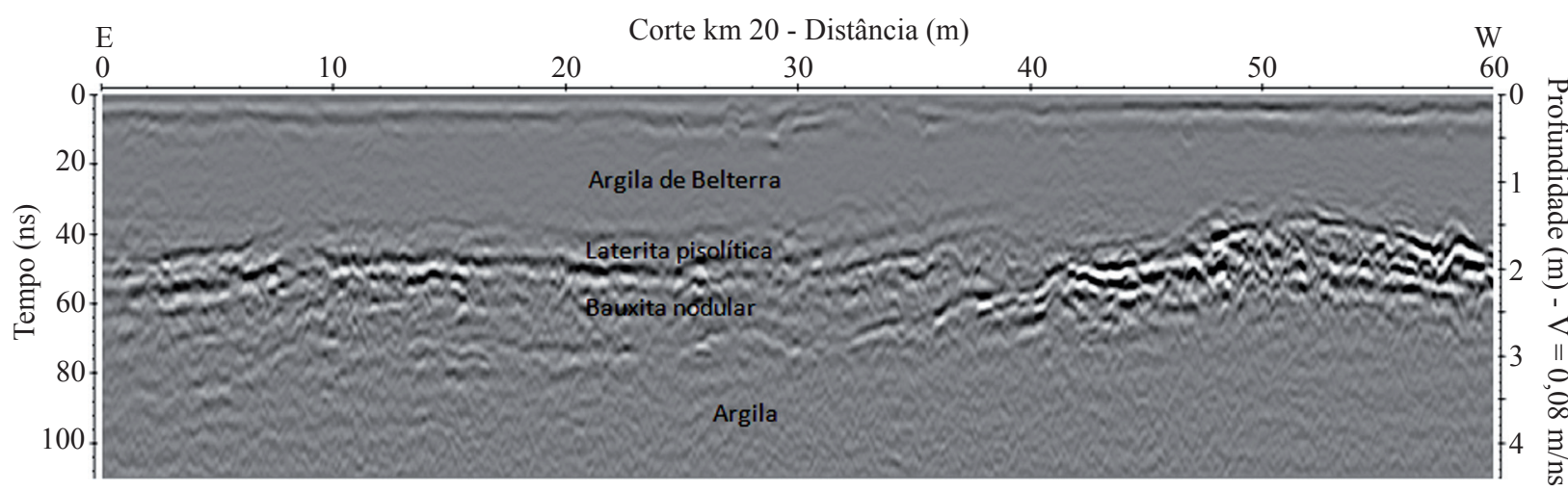

Figura 10 - Perfil realizado com antenas de $200 \mathrm{MHz}$ sobre corte do km 20 da Rodovia PA-256. 
O perfil mostra a interface de reflexão que foi associada ao contato entre as camadas de goethita e do argilito siltoso. As camadas de goethita são caracterizadas por reflexões fortes e contínuas, enquanto o argilito siltoso apresenta um padrão de reflexões bastante atenuadas. É possível observar, também, uma série de reflexões descontínuas, que foram interpretadas como produzidas pelo granito. Na Fig. 14 está o perfil teste executado com antenas blindadas de $200 \mathrm{MHz}$ no mesmo local daquele mostrado na Fig. 13. O perfil exibe mais detalhadamente as reflexões visualizadas naquele adquirido

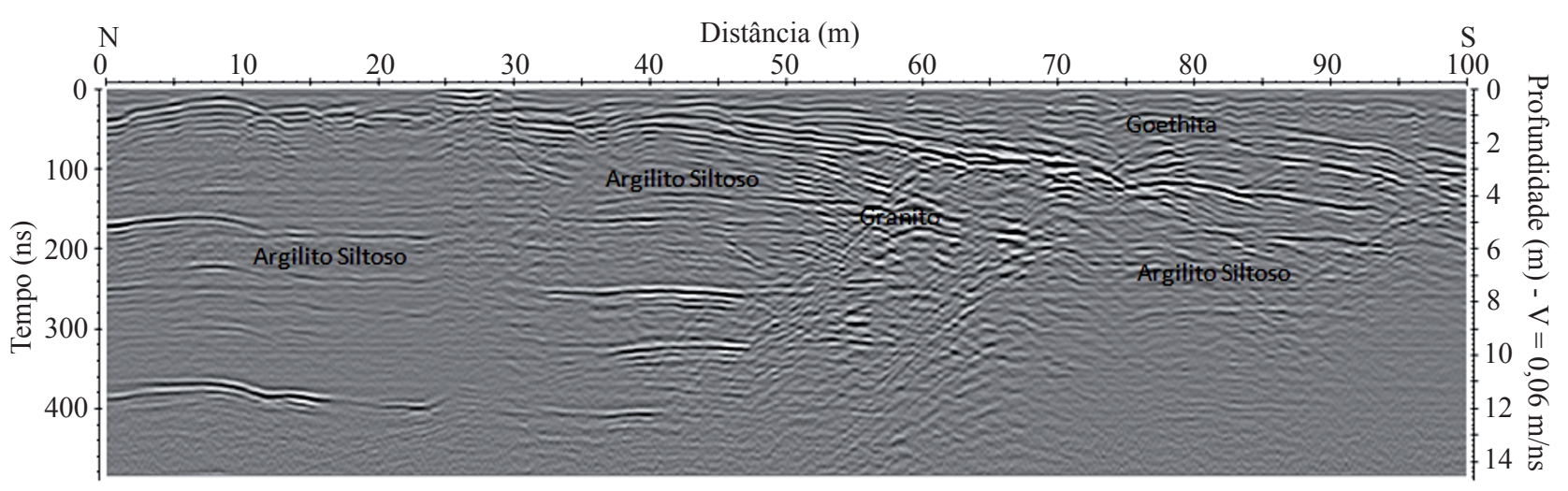

Figura 13 - Perfil teste adquirido com antenas não blindadas de $80 \mathrm{MHz}$.

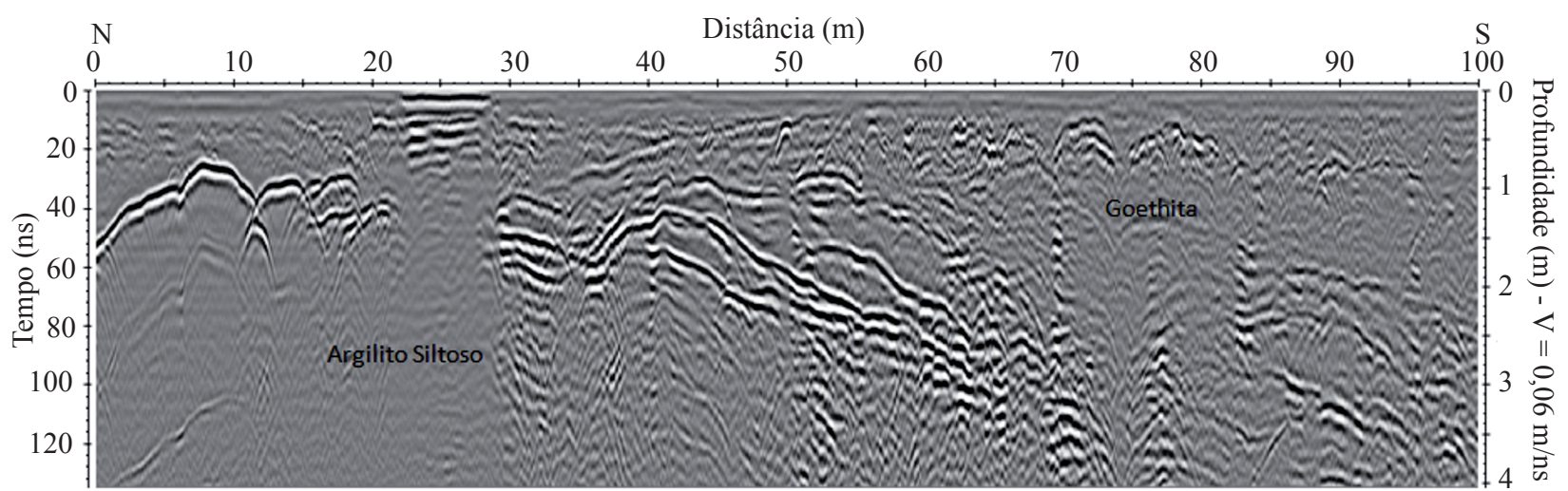

Figura 14 - Perfil teste adquirido com antenas blindadas de $200 \mathrm{MHz}$.

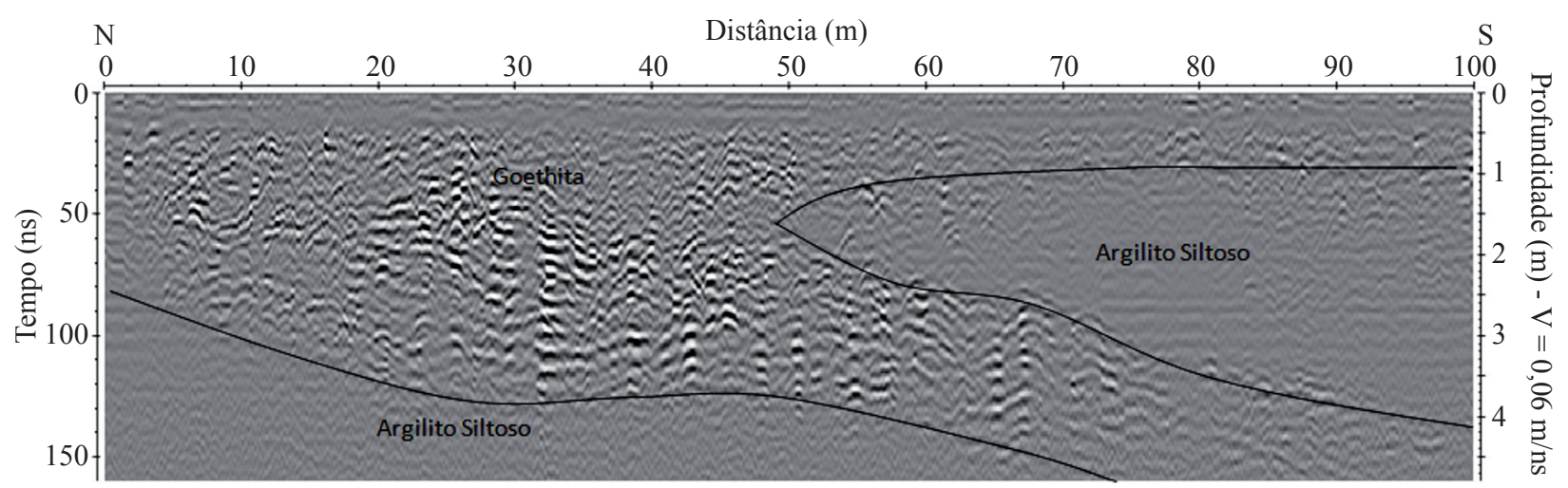

Figura 15 - Primeira seção do perfil adquirido com as antenas de $200 \mathrm{MHz}$ no interior da fazenda. 
com a antena de $80 \mathrm{MHz}$. As medidas nesse perfil atingiram profundidade de $4 \mathrm{~m}$ e mostram com mais clareza a interface goethita e argilito siltoso.

Após o teste, decidiu-se utilizar as antenas de $200 \mathrm{MHz}$ na execução do perfil realizado no interior da fazenda, devido à melhor resolução obtida e à maior praticidade na manipulação dessas antenas em relação às de $80 \mathrm{MHz}$. Para garantir o mapeamento da base da zona mineralizada, ampliou-se a profundidade de investigação utilizando

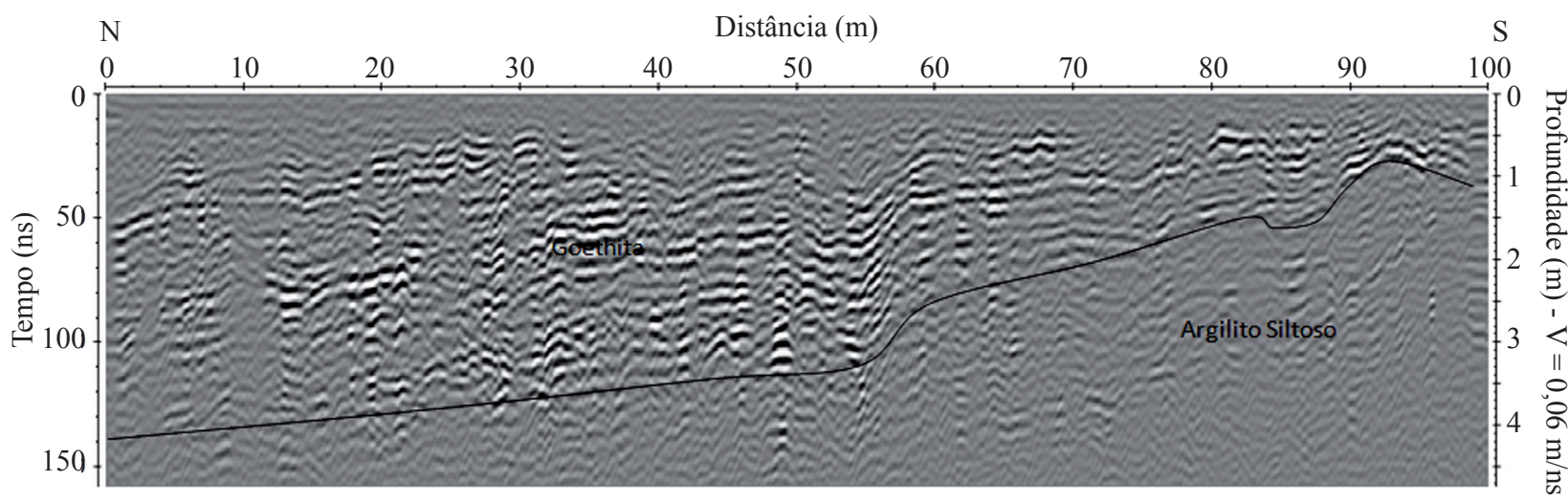

Figura 16 - Segunda seção do perfil adquirido com as antenas de $200 \mathrm{MHz}$ no interior da fazenda.

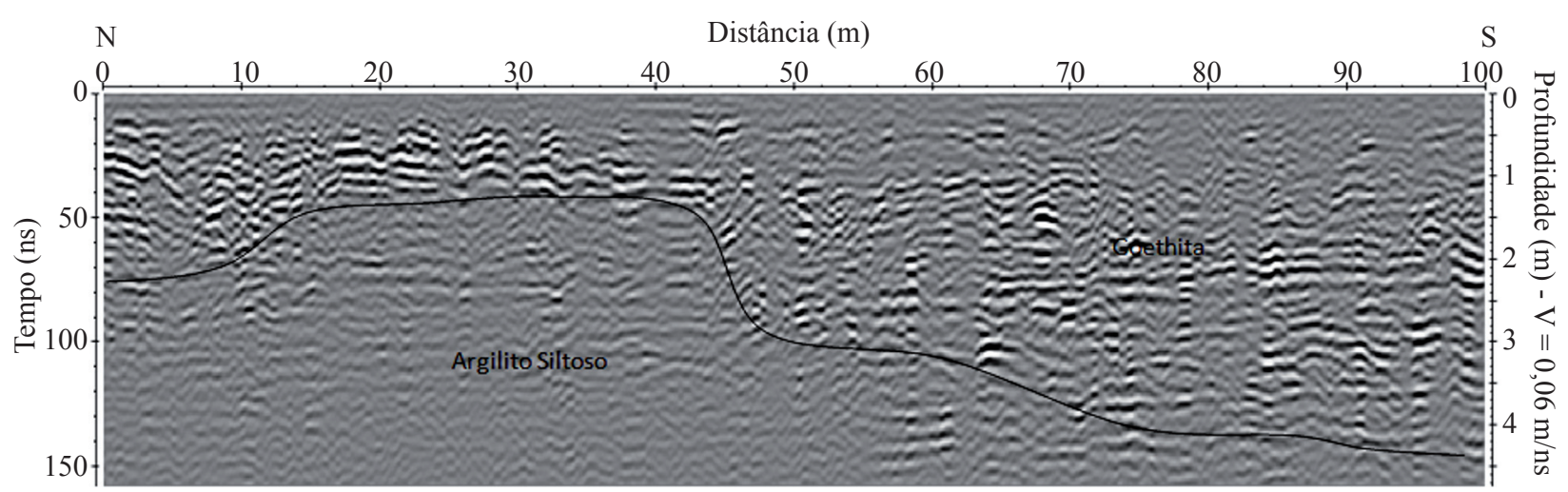

Figura 17 - Terceira seção do perfil adquirido com as antenas de $200 \mathrm{MHz}$ no interior da fazenda.

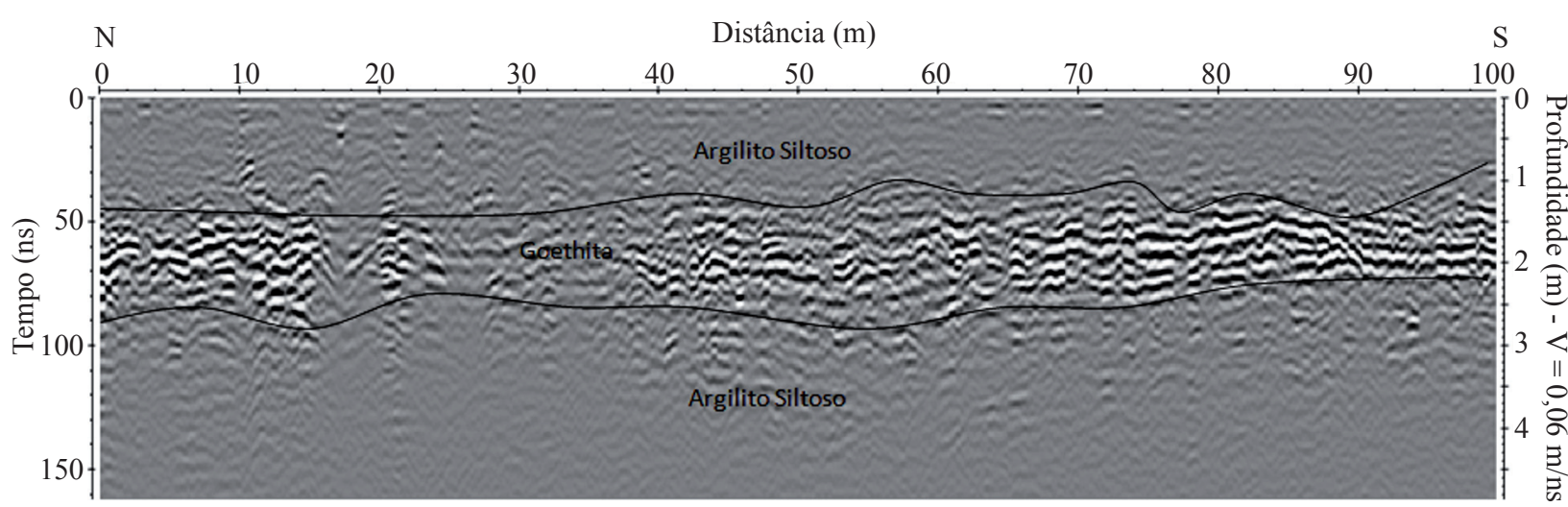

Figura 18 - Quarta seção do perfil adquirido com as antenas de $200 \mathrm{MHz}$ no interior da fazenda. 
uma janela de amostragem de $150 \mathrm{~ns}$, superior a de 120 ns usada no teste.

O perfil executado na área da fazenda tem $400 \mathrm{~m}$ de extensão e foi dividido em quatro seções de $100 \mathrm{~m}$. As Figs. 15 a 18 mostram as quatro seções interpretadas. As regiões com fortes reflexões foram associadas à goethita e as regiões com forte atenuação, ao argilito siltoso.

CONCLUSÕES Com a utilização das antenas blindadas de $200 \mathrm{MHz}$, na mina de bauxita, não foi possível obter informações sobre a zona do minério no local onde havia capeamento argiloso de espessura aproximada de $12 \mathrm{~m}$, devido à atenuação da onda eletromagnética transmitida pelo GPR. Os levantamentos realizados sobre zonas sem o capeamento de argila foram muito bem-sucedidos, tanto com as antenas blindadas de $200 \mathrm{MHz}$, quanto com as de $400 \mathrm{MHz}$, permitindo-se a visualização de refletores associados às interfaces entre camadas. As medidas realizadas sobre as zonas mineralizadas sem capeamento foram importantes, pois tornaram possível a visualização, em detalhes, das ondulações das camadas, o que possibilita a orientação para a lavra do minério e melhora a estimativa de cubagem da jazida.

Os levantamentos realizados no interior da mina de bauxita e os realizados nos cortes expostos ao longo da Rodovia PA-256 tornaram possível a associação da sequência de camadas obtidas no radargrama com a do perfil litológico. Com os resultados obtidos, concluiu-se que é possível a utilização desse método na prospecção de bauxita laterítica.

No mapeamento de camadas em depósitos de goethita, assim como no caso da bauxita, foi obtida uma boa resposta no que diz respeito à profundidade alcançada e à caracterização dos refletores relacionadas às interfaces entre camadas. A aquisição de dados com as antenas não blindadas de $80 \mathrm{MHz}$ foi bem-sucedida em relação à profundidade alcançada, o que permitiu a verificação da espessura máxima da zona mineralizada, porém em relação à resolução, o resultado não foi muito satisfatório. Já com as antenas blindadas de $200 \mathrm{MHz}$, os resultados foram melhores em relação à resolução e à praticidade em seu manuseio. A geologia da região é bastante favorável à utilização do método, pois não há capeamento argiloso antecedendo a zona mineralizada, como no caso da bauxita. Os contrastes entre as camadas de goethita e de argilito siltoso foram bem caracterizadas nos radargramas, o que possibilitou estimar suas espessuras. A utilização das antenas de $200 \mathrm{MHz}$ foi eficiente na pesquisa, pois o maior interesse era caracterizar a zona mineralizada de goethita. Com os resultados obtidos, foi possível observar a utilização do método GPR na prospecção de goethita em áreas de geologia semelhante.

\section{AGRADECIMENTOS Ao Programa}

de Pós-graduação em Geofísica do Instituto de Geociências da Universidade Federal do Pará (UFPA) pela oportunidade de desenvolvimento desta pesquisa e ao Departamento de Operações Bauxita Paragominas, da Empresa Vale, pelo suporte logístico deste trabalho e por ceder a área de sua mina de bauxita para a realização das investigações. Aos alunos de Graduação que fizeram parte do grupo da disciplina GT II (Grupo de trabalho II) de 2010. Ao técnico Paulo Magalhães pela importante assistência no trabalho de campo. Ao Conselho Nacional de Desenvolvimento Científico e Tecnológico (CNPq) por ter proporcionado uma bolsa para Gildenilson Mendes Duarte durante o desenvolvimento de sua pesquisa. Aos revisores da RBG pelas excelentes sugestões, as quais ajudaram a melhorar o texto do artigo.

\section{Referências}

Amaro G.J.L. 2011. Ironstones da base da Formação Pimenteiras, borda Noroeste da Bacia do Parnaíba, região Xambioá-Colinas do Tocantins. Dissertação de Mestrado, Instituto de Geociências, Universidade Federal do Pará, Pará, 90 p.

Botelho M.A.B. 2007. Prospecção de Manganês com Radar de Penetração no Solo (GPR) no Oeste da Bahia. In: $10^{\text {th }}$
International Congress of the Brazilian Geophysical Society, Rio de Janeiro (disponível em CD).

CPRM. 2008. Geologia e recursos minerais do estado do Pará. Belém, Ministério de Minas e Energia, 328 p.

Ekes C., Hickin A., Matysek P., Kinnan E. 2002. Application of ground penetrating radar in placer mining, a case study from Guyana's potaro region. In: 
International conference on ground penetrating radar N9, 4758:685-690.

Hickin A.S., Bobrowsky P.T., Paulen R.C., Best M. 2007. Imaging fluvial architecture within a paleovalley fill using ground penetrating radar, Maple Creek, Guyana. In: Baker G.S., Jol H.M. (Ed.) Stratigraphic analysis using GPR. Geological Society of America Special Paper 432, p. 133-153.

Kearey P., Brooks M., Hill I. 2009. Geofísica de exploração. São Paulo: Oficina de textos, 438 p.

Kotschoubey B., Calaf J.M.C., Lobato A.C.C., Leite A.S., Azevedo C.H.D. 2005. Caracterização e gênese dos depósitos de bauxita da Província Bauxitífera de Paragominas, noroeste da bacia do Grajaú, nordeste do Pará/oeste do Maranhão. In: Marini O.J., Queiroz E.T., Ramos B.V. (Eds.) Caracterização de depósitos minerais em distritos mineiros da Amazônia. Brasília, DNPMCT/ Mineral-ADIMB, p. 691-782.

Luiz J.G. 1998. Notas de aulas sobre o método Georadar. Belém: Universidade Federal do Pará, 8 p.
Luiz J.G. \& Silva L.M.C. 1995. Geofísica de prospecção. Belém: Universidade Federal do Pará. Cejup, 311 p.

Porsani J.L., Mendonça C.A., Bettencourt J.S., Hiodo F.Y., Vian J.A.J., Silva J.E. 2004. Investigações GPR nos distritos mineiros de Santa Bárbara e Bom Futuro: Província estanífera de Rondônia. Revista Brasileira de Geofisica, 22:57-68.

Silva J.E., Yokoyama L.M.L., Silva, V.A., Hiodo F.Y., Moutinho L. 2010. Levantamento geofísico visando testar a metodologia do radar de penetração no solo (GPR) na pesquisa mineral de bauxita. In: IV Simpósio de Brasileiro de Geofísica, Brasília, 2010. Resumos Expandidos, Sociedade Brasileira de Geofísica (disponível em CD).

Manuscrito ID 22955

Recebido em: 02/09/2011

Aprovado em: 07/03/2012 